\title{
A Study on Strategy Instruction and EFL Learners' Writing Skill
}

\author{
Giti Mousapour Negari \\ Department of English Language \& Literature \\ University of Sistan \& Baluchestan, Zahedan, Iran \\ Tel: 98-541-805-6622Ｅ-mail: mousapour@hamoon.usb.ac.ir
}

Received: June 20, 2011 Accepted: August 3, $2011 \quad$ doi:10.5539/ijel.v1n2p299

\begin{abstract}
Writing in a second or foreign language seems to be the most difficult language skill for language learners to acquire in academic contexts. While explicit instruction of strategies is not a usual practice in foreign language classrooms, it could be beneficial for language learners. The present study aims at investigating the effect of concept mapping strategy on EFL learners' writing performance. To this end, sixty Iranian students at the intermediate level of language proficiency participated in the study. Their language proficiency was determined by Michigan Test of English Language Proficiency. The results of the Analysis of Covariance revealed that the instruction of concept mapping strategy had a positive effect on EFL learners' writing achievements. The findings have some pedagogical implications for teaching language skills and designing strategy-based syllabus leading to successful language performance.
\end{abstract}

Keywords: Concept mapping, Explicit instruction, Learning strategy, Writing achievement

\section{Introduction}

Writing is a complicated process which involves a number of cognitive and metacognitive activities, for instance; brainstorming, planning, outlining, organizing, drafting, and revising. Cognitive aspects of writing have received a particular attention, as investigators have attempted to understand the thought processes underlying the compositions of students (Flower \& Hayes, 1981). According to Omaggio Hadley (1993), writing requires composing, which implies the ability either to tell or retell pieces of information in the form of narratives or description, or to transform information into new texts, as in expository or argumentative writing. Therefore, it is best viewed as a continuum of activities that range from the more mechanical or formal aspects of writing down on the one end to the more complex act of composing on the other end.

A substantial body of research suggests that training students to use language learning strategies can help them become better language learners. Early research on "good language learners" (Naiman, Fröhlich, Stern, \& Todesco, 1996) suggested a number of learning strategies that successful students employ when they learn a second or a foreign language. A study of O'Malley and Chamot (1990) suggested that effective L2/FL learners are aware of the learning strategies they use and why they use them. Meaningful learning according to Ausubel's (2000) theory occurs when students intentionally attempt to integrate new knowledge with existing knowledge. A learner who attempts to integrate knowledge has a more extensive network of knowledge and therefore more retrieval paths. Richards, Platt, and Platt (1992) presented a specific definition of strategy training and outlined three different approaches: "[It is] training in the use of learning strategies in order to improve a learner's effectiveness. A number of approaches to strategy training are used including: 1) Explicit or direct training: learners are given information about the value and purpose of particular strategies, taught how to use them and how to monitor their own use of the strategies. 2) Embedded strategy training: the strategies to be taught are not taught explicitly but are embedded in the regular content of an academic subject area, such as reading, math or science. 3) Combination strategy training: explicit strategy training is followed by embedded training" (p. 355).

Learning to write is difficult especially for those writing in a second or a foreign language in academic contexts since they do not know enough about how to generate ideas for writing. As effective writing is considered to be a problem for EFL learners, a need is felt to find out some ways of teaching that can help learners improve their writing performance. The main purpose of this study is to investigate the effectiveness of explicit instruction of strategies, namely concept mapping, on EFL learners' writing improvement.

\section{Review of the related literature}

Teaching writing skill in a second or a foreign language has passed different trends, each of which has had benefits and shortcomings. Process-writing arose in the late 1960s and the early 1970s in reaction to the dominance of a product-centered pedagogy. According to Fujieda (2006), this trend resulted from process-based research in L1 composition. It was considered to be important in that it brought meaningfulness to learners who 
wrote while making a personal connection to the topic and the processes related to it. This starts with brainstorming and prewriting to organize the ideas and activate the schemata, which refers to the knowledge of the world that a person possesses that allow him to relate background experience to the topic and discover everything he intends to say (Tribble, 1996).

The attention to the writer as creator of text as Raimes (1991) declared has led to a process approach, with a new set of classroom activities characterized by the use of journals, invention, peer collaboration, revision, and attention to content before form. It focuses on the writer as an independent producer of texts so that teachers help their learners develop students' abilities to plan, define a problem and suggest and evaluate solutions (Hyland, 2003). A concern with the process approach is that writers generate the original tasks with their own feelings and emphasize fluency rather than accuracy (Ferris \& Hedgcock, 2005).

Academic writing demands much effort and practice in composing, organizing, and analyzing ideas. Students writing in a foreign language will naturally face with cognitive problems related to language learning. Sturm and Rankin-Erickson (2002) stated composing is an advanced academic task within educational settings and parts of the students' difficulties in writing are related to difficulties in applying various cognitive strategies. Sturm and Rankin-Erickson further stated that strategy instruction is a teaching approach that assists students in developing strategies for all phases of the writing process by breaking down writing tasks and making the subprocesses and skills much more explicit. A survey of literature reveals that many teachers tried to influence the course of this development in a relatively straightforward and direct fashion. They might model and explicitly teach the types of strategies used by more skillful writers, or might predict routines where writing processes such as planning and revising were expected and strengthened (Graham \& Harris, 1996). This view toward explicit teaching of learning strategies has marked a continued investigation into learning processes and support for the communicative philosophy of teaching learners how to learn, and thus become independent and autonomous learners through the use of learning strategies (Wenden, 1991). Brown (2000) acknowledged work on the effectiveness of learning strategies for various learners in a variety of contexts. Brown stated "...we probe its implications for your teaching methodology in the classroom, specifically, how your language classroom techniques can encourage, build, and sustain effective language-learning strategies in your students" (p.130).

Literature reports on the benefits of concept mapping for organizing information, assessing in learning, comprehension of particularly complex communications, refining literacy framework, and successful understanding of the text (Ruddell \& Boyle, 1989). Concept mapping, as a learning strategy, is defined as a visual representation of an individual's knowledge structure on a particular topic as constructed by the individual (Zimmaro \& Cawley, 1998). Concept mapping is assumed to be an excellent exercise for the promotion of creative thinking and identification of new problem- solving methods (Cañas et al., 2003).

Concept mapping primarily being a knowledge representation has become a tool actively used by students during learning. The process of concept mapping not only demands active involvement of the learner in the learning process but also sheds light on their understanding of a specific learning area. Instructionally, as Zimmaro and Cawley (1998) stated concept maps foster meaningful learning by teaching connections among concepts. Strategies such as concept mapping helps learners engage in meaningful activities. As Mayer (2003) described three processes which are required for meaningful learning to take place. These are: attend, organize, and integrate. Learners must pay attention to the relevant and important content, they must organize the content structurally, and they must integrate the content into their existing cognitive structure. Strategy teaching can therefore be summarized as teaching learners how to learn, with a view to become independent and autonomous learners.

Badger and White (2000) believed that the process approach to writing has its own limitations. It regards all writing as being produced by the same set of processes and it offers learners insufficient input, particularly in terms of linguistic knowledge to write successfully. In the 21 th century a new view toward social issues, the post-process, has developed in second language writing. Process writing which was supposed to be a strong guiding force in the late twentieth century was criticized as asocial. It considered the learners as individuals, the writing process as something abstract which contains internal processes. Writing was assumed to be a discovery activity, what was being discovered was the self (Kent, 1999 as cited in Atkinson, 2003). According to Fujieda (2006), the period of post-process era emphasizes social dimensions to writers ignoring cognitive science to exceed prevalent points of view in L2 writing research and teaching.

Despite all the limitations of process writing, Matsuda (2003) argued that "the notion of post-process needs to be understood not as the rejection of process but as the recognition of the multiplicity of L2 writing theories and pedagogies" (p.65). Atkinson (2003) elaborated on the concept of post-process and declared "The usefulness and power of process writing has been revealed time and again; and if I were suddenly transported into and put in charge of an L2 writing classroom, pre-writing, drafting, feedback, and revising would almost certainly be important classroom activities. As an approach to teaching different kinds of writing at the university level, I personally hold process writing in high regard - it is, in fact, difficult for me to conceptualize the effective 
teaching of writing without it. My own interest in the concept of "post-process" is, therefore, not in terms of a basic "paradigm shift," but rather in expanding and broadening the domain of L2 writing - in research as much as in teaching"(p.10).

Therefore, there will be no definite answer to the question of which approach to writing is more effective. Rather, the idea of seeking the best method is misleading. In fact, all the different approaches to writing are complementary to and compatible with each other (Hyland, 2002 as cited in Yang, 2005). Second or foreign language writing requires much more studies on different grounds to discover how to apply theories in writing practices and in different settings as the field of teaching writing skill is still developing.

\section{Methodology}

\subsection{Restatement of the problem}

A large number of descriptive studies of language learning strategies reveal significant differences between more and less successful learners. They inquire the possibility of teaching learners to use the learning strategies that contribute to the achievements of their more successful peers. Proponents of language learning strategy instruction point to the substantial body of research in first language contexts that supports the explicit teaching of learning strategies for academic achievement in other content areas (De La Paz \& Graham, 2002; Graham \& Harris, 2000; Pressley, 2000). As strategy instruction has been proved to improve performance on first language tasks such as vocabulary learning, reading comprehension, and writing, it is likely that it could be equally helpful for second or foreign language learners in different tasks. This study tries to answer the following question:

To what extent does concept mapping strategy improve learners' writing performance in an EFL setting?

\subsection{Design}

The study had a pretest-posttest control group design. Prior to the instruction of concept mapping strategy, both control and experimental groups were administered pretests in writing. To explore the effectiveness of concept mapping strategy both groups participated in posttests writing tasks at the end of the instructional period. Only the experimental group received the treatment.

\subsection{Participants}

Ninety Iranian university students volunteered to participate in the study. They were studying English and had passed two English writing courses including sentence patterns and paragraph development. They ranged from 18 to 22 years old. Michigan Test of English Language Proficiency (MTELP) was used to determine the students' level of English proficiency. According to the mean and standard deviation of the test, the students whose scores fell one standard deviation below and above the mean were assigned as the intermediate group. Of the sixty students at the intermediate level of proficiency, thirty students were randomly assigned to the control group and thirty students to the experimental group. In the experimental group, twelve students were male and eighteen students were female. In the control group, ten students were male and twenty students were female

The treatment for the experimental group was instruction and practice in concept mapping strategy. Students in the experimental group were provided with handouts that included definition of concept mapping, different uses and examples of concept maps. Students practiced the application of concept mapping in writing essays. They were required to draw concept maps of their own or to complete the incomplete maps (See Appendix for more detailed information about instruction and practice of concept mapping strategy). They practiced writing expository essays, using concept mapping strategy. The topics for the essays sequenced from easy and familiar topics (unnecessary to have specialized knowledge) to difficult and unfamiliar topics. They included: plants, time, weather, air pollution, the function of heart, and psychology. Familiarity/unfamiliarity and simplicity/difficulty of the topics were judged by three university teachers who were teaching writing courses for many years. The control group wrote essays about the same topics without the use of concept mapping strategy.

\subsection{Instruments}

The instruments used to determine the level of the students' English proficiency was Michigan Test of English Language Proficiency; and essay writing tasks were applied to measure the students' writing ability. First, the students were asked to participate in the test of language proficiency. From among ninety students, sixty students at the intermediate level of English language proficiency were randomly selected. The students whose scores fell one standard deviation below and above the mean were assigned as the intermediate group. Then the students in the two groups were asked to write two expository essays on given topics (1.The best teacher 2.An interesting book or TV show) before the instruction (pretest) and after the instruction (posttest). The topics for the pretest and posttest were the same. Compositions were then scored out of 20. The students' papers were scored by two raters who taught writing courses in the university for many years. Interrater reliability for the pretest and posttest were .87 and .85 respectively.

\subsection{Procedure}

Instruction period was about twelve weeks (about one semester in the university) and comprised of three phases: 


\subsubsection{Pre-testing}

Before the students in the experimental group received any instruction, all the students in the two groups were asked to write two essays about the given topics. The allotted time for each topic was forty five minutes. The papers were collected and each student's score was measured based on the average score for the two raters.

\subsubsection{Strategy Instruction}

The strategy instruction phase started a week after the students participated in the pretest. They participated in twelve sixty-minute study sessions. The students in the experimental group received the instruction for concept mapping strategy. The strategy was taught following Harris and Graham (1996):

1. Strategy description. As an introduction to the first lesson, students were told that they were going to learn about the strategy of concept mapping. Concept mapping was described as a strategy that could be used to categorize information in a graphic form through drawing. It is also used for vocabulary development, reading comprehension, study skills, and prewriting activities. Finally, the sequence of steps for creating a concept map was described.

2. Discussion of goals and purposes. The teacher discussed the students about the significance and benefits of using the concept mapping strategy in writing compositions. Students were asked two questions: (1) How do you think this strategy might help you write? And (2) How could this strategy help you with different types of writing?

3. Modeling the strategy. The teacher modeled use of concept mapping strategy by creating a map while students were offered several topics to select from for the activity. Once the group agreed on a topic, the teacher wrote it on the white board. This topic was labeled as "main idea" of the concept map. Next possible subtopics were generated. Students were taught how to write subtopic information in telegraphic form. The teacher modeled use of telegraphic language forms and explained that this involves choosing the most important information. Upon completion of the map , the teacher modeled the transfer of subtopic information from the map into written forminstruction followed the sequence of procedures for transferring concept maps into written paragraphs, starting with top-level structures i.e., topics and subtopics ), the teacher reviewed the information on the map. The teacher modeled how she would rewrite the information from the map into complete sentences. Finally, the concluding paragraph was explained and with the help of the students the teacher wrote a concluding paragraph.

4. Student mastery of strategy steps. During this stage, students rehearsed and memorized the sequence of activities for concept map construction.

5. Guided practice and Feedback. During these sessions, feedback was provided for students' performance. Students chose a topic and created maps. Then, they used the concept maps to compose essays.

The first three sessions were devoted to training the technique. The other nine sessions were spent on practicing the strategy for the students to master the fundamental skills. One essay was composed every two weeks for a total of four essays for each student. During these sessions, other formal teaching techniques were not employed by the teacher. The teacher was a non-native English teacher who had taught writing courses for many years. He had been trained by the researcher how to instruct the strategy in the classroom. The same teacher taught the students in the control group with the same hours of instruction but without using concept mapping strategy.

\subsubsection{Post-testing}

A week after the instruction period of the strategy of concept mapping all the students in two groups again wrote essays about the given topics. The papers were collected and each student's score was measured based on the average score for the two raters.

\subsubsection{Scoring}

To measure the students' ability in writing, they were asked to write essays. Essays were then scored based on Jacobs et al. (1981, as cited in Weigle, 2002). In Jacobs et al. scale each paper was rated on five aspects of writing: content, organization, vocabulary, language use, and mechanics. The five aspects have different weights according to their emphasis: Content (30 points), language use (25 points), organization and vocabulary weighted equally (20 points) and mechanics receiving very little emphasis ( 5 points).

Compositions were scored by two university teachers who taught writing courses for many years. For each paper, examiners were required to read the paper attentively and to combine the scores into a single score. Spelling and handwriting were not taken into consideration by the raters. Essays were then scored out of 20. Interrater reliability for the pretest and posttest compositions were .87 and .85 respectively. The final score for each student was the average score for the two raters. 


\section{Results and Discussion}

The major question addressed in this study was whether the use of concept mapping strategy would improve EFL students' writing achievement at the intermediate level of language proficiency. Initially, descriptive statistics for the subjects' performances on writing tests were computed. Table 1 summarizes basic descriptive statistics including means and standard deviations of pretest and posttest scores on writing achievement tests of the two groups. (Table 1)

A comparison of mean scores of the experimental group and the control group on posttests shows that the participants in the experimental group outperformed on post essay writing tests in comparison with the control group. In other words, the learners' performances in the control group were lower than the experimental group. To explore the significant differences in the performances of the two groups, an ANCOVA on Post writing achievement scores by group (experimental vs. control), using Pre writing achievement scores as a covariate, was run. The results of the ANCOVA $(\mathrm{F}=100.92, p=.000<.05)$ indicated that the difference between the two groups is meaningful. In other words, it shows that there is a significant difference in the posttest scores between the two groups. (Table 2)

The results of the present study indicated that the explicit instruction of concept mapping strategy which led to its application by the learners, significantly affected the learners' writing performances. The findings proved that explicit instruction of strategies that led to the student's awareness was effective in the students' writing tasks. The emphasis on the processes of writing in a second or foreign language, despite the challenges against process writing, will lessen the complexity and the difficulty of the writing tasks both for learners and teachers.

The finding of the present study is consistent with the findings of Zipprich (1995) and Peresich, Meadows, and Sinatra (1990), which provided evidence for the positive effects of concept mapping strategy on academic writing. The findings also support Schunk's (1998) claim holding that students who believe they are learning a useful strategy are apt to feel efficacious about improving their writing.

Freeman (2002) provides an explanation for the effect of concept mapping strategy on the writing process. Freeman states that human minds have the ability to create conceptual objections from the concrete to abstract by the process of mapping from past to present. The ability to create multiple mappings of mental spaces enables us to construct new conceptualizations of the world and create abstract thoughts in the world.

Another possible explanation for the positive effect of concept mapping strategy on the learners' writing achievement is provided by Cicognani (2000), holding that by the visual representation of keywords on a map, a learner is able to refine language and vocabulary, identify the key issues, organize these key issues into a meaningful chart, and reuse the map in the future with a reasonable success. The learners do not get lost; they have a referring map to which they can come back to review previous steps and to organize the new information.

\section{Conclusion and Implications}

As the study proved the application of concept mapping strategy by the learners, through the explicit instruction of the strategy, can help them improve their writing performance. Through concept mapping, students can easily understand and organize their thoughts in pictorial representations. In other words, graphical representation of ideas increases the students' conceptual understanding which in turn helps them organize their ideas. The study reveals the effectiveness of concept mapping technique for the students' writing tasks which supports what Atkinson (2003) stated, “... by advocating a post-process approach to L2 writing I do not intend to suggest that process pedagogy should necessarily be replaced in any wholesale way in the L2 writing classroom (p. 10)." Atkinson further stated in the post- process "we seek to highlight the rich, multifocal nature of the field" and "go beyond now-traditional views of L2 writing research and teaching" (p.12).

The paper has some implications for language teaching and learning. The students can become better learners if they become more aware of their learning processes and then decide to act on that awareness. Teachers may increase their students' confidence in writing by familiarizing them with the concept mapping strategy. Likewise, the paper has some implications for syllabus design. Concept-based teaching can teach students to classify and to reinforce the students' creativity and self-awareness. Not only is this way of teaching useful for writing but also enhances students' sense of retention, understanding, problem-solving ability and classroom performance. Hence, it will be very useful for teaching other skills too.

Although the present study suggests that the strategy of concept mapping is beneficial to university students, there are areas that need to be studied further. One area for further research is integrating learning strategies into classroom instruction. The teacher may provide some models for applying various strategies in different skills. Another area for doing more research is to conduct such studies with a variety of language students, including school-aged students and students with different educational backgrounds.

Applying the concept mapping strategy is neither the only way nor the best way to improve students' writing skill. There are many methodological issues which need to be explored in order to improve the process described 
here. However, one of the important considerations in preventing or overcoming writing difficulties is helping EFL writers master the cognitive aspects of composing.

\section{References}

Atkinson, D. (2003). L2 writing in the post-process era. Journal of Second Language Writing, 12(1), 3-15. doi:10.1016/S1060-3743(02)00123-6, http://dx.doi.org/10.1016/S1060-3743(02)00123-6

Ausubel, D. P. (2000). The acquisition and retention of Knowledge: a cognitive view. Boston: Kluwer Academic Publishers.

Badger, R. \& White, G. (2000). A Process Genre Approach to Teaching Writing. ELT Journal, 54(2), 153-160. doi:10.1093/elt/54.2.153, http://dx.doi.org/10.1093/elt/54.2.153

Brown, H. D. (2000). Principles of Language Learning and Teaching. (Fourth Edition) New York: Longman.

Cañas, A., Coffey, J., Carnot, M., Feltovich, P., Hoffman R., \& Feltovich, J. (2003). A summary of literature pertaining to the use of concept mapping techniques and technologies for education and performance support. [Online] Available: https://carmenwiki.osu.edu/download/attachments/15599855/IHMC+Literature+Review+on+Concept+Mapping. pdf (July 2003)

Cicognani, A. (2000). Concept Mapping as a Collaborative Tool for Enhanced Online Learning. Educational Technology \& Society, 3(3), 150-158.

De La Paz, S., \& Graham, S. (2002). Explicitly teaching strategies, skills, and knowledge: Writing instruction in middle school classrooms. Journal of Educational Psychology, 94(4), 687-698. doi:10.1037/0022-0663.94.4.687, http://dx.doi.org/10.1037/0022-0663.94.4.687

Ferris, Dana, \& Hedgcock, John, S. (2005). Teaching ESL Composition: Purpose, Process, and Practice. 2nd ed. Mahwah: Lawrence Erlbaum.

Flower, L. \& Hayes, J. R. (1981). Plans that guide the composing process. In C. H. Frederiksen, \& J. F. Dominic (Eds.). Writing: the nature, development, and teaching of written communication, Vol. 2: Writing: process, development and communication (pp.39-58). Hillsdale, N J: Lawrence Erlbaum Associates.

Freeman, M. H. (2002). Cognitive mapping in literacy analysis. Los Angeles Valley College. EBSCO Publishing.

Fujieda, Y. (2006). A Brief Historical Sketch of Second Language Writing Studies: A Retrospective. [Online] Available: www.kyoai.ac.jp/college/ronshuu/no-06/fujieda.pdf (March 2006)

Graham, S. \& Harris, K. (1996). Self-regulation and strategy instruction for students who find writing and learning challenging. In M. Levy \& S. Ransdell, (Eds.). The science of Writing: Theories, methods, individual differences and applications, (pp. 347-360). Mahwah, NJ: Lawrence Erlbaum.

Graham, S. \& Harris, K. (2000). The role of self -regulation and transcription skills in writing and writing development. Educational psychologist, 35(1), 3-12. doi:10.1207/S15326985EP3501_2, http://dx.doi.org/10.1207/S15326985EP3501_2

Harris, K. R. \& Graham, S. (1996). Making the writing process work: Strategies for composition and self-regulation. Cambridge, MA: Brookline Book.

Hyland, K. (2003). Second Language Writing. Cambridge: Cambridge University Press.

Jonassen, D. H., \& Grabowski, B. L. (1993). Handbook of individual differences, learning, and instruction. Hillsdale, NJ: Erlbaum.

Matsuda, P. K. (2003). Process and post-process: A discursive history. Journal of Second Language Writing 12 (1), 65-83. doi:10.1016/S1060-3743(02)00127-3, http://dx.doi.org/10.1016/S1060-3743 (02)00127-3

Mayer, R. E. (2003). The promise of Educational psychology: Teaching for meaningful learning. Merrill Prentice Hall.

Naiman, N., Fröhlich, M., Stern, H. H., \& Todesco, A. (1996). The good language learner. Clevedon, England: Multilingual Matters.

Omaggio Hadley, A. (1993). Teaching language in context. Boston: Heinle \& Heinle.

O'Malley, J. M., \& Chamot, A. U. (1990). Learning strategies in second language acquisition. Cambridge, UK: Cambridge University Press.

Pressley, M. (2000). What should comprehension instruction be the instruction of? In M. L. Kamil, P. B. Mosenthal, P. D. Pearson, \& R. Barr (Eds.), Handbook of reading research: Volume III, (pp. 545-561). Mahwah, NJ: Erlbaum. 
Raimes, A. (1991). Out of the woods: Traditions in the teaching of writing. TESOL Quarterly, 25, 407-430. doi:10.2307/3586978, http://dx.doi.org/10.2307/3586978

Richards, J. C., Platt, J., \& Platt, H. (1992) Dictionary of Language Teaching \& Applied Linguistics. (Second Edition), Harlow, Essex: Longman.

Ruddell, R. B., \& Boyle, O. F. (1989). A study of cognitive mapping as a means to improve summarization and comprehension of expository text. Reading Research and Instruction, 29(1), 12-22.

Schunk, D. (1998). Teaching elementary students to self-regulate practice of mathematical skills with modeling. In D.H. Schunk \& B.J. Zimmerman, (Eds.) Self-regulated learning; from teaching to self-reflective practice (pp. 137-159). New York: The Guilford Press.

Sturm, J. \& Rankin-Erickson, J. (2002). Effects of hand-drawn and computer generated concept mapping on the expository writing of middle school students with learning disabilities. Learning Disabilities Research and Practice, 17(2), 124-139. doi:10.1111/1540-5826.00039, http://dx.doi.org/10.1111/1540-5826.00039

Tribble, C. (1996). Writing. Oxford: Oxford University Press.

Weigle, S.C. (2002). Assessing writing. Cambridge University Press.

Wenden, A. L. (1991). Learner strategies for learner autonomy. London: Prentice-Hall International.

Yang, M. (2005). Exploring writing approaches in Chinese EFL class. Academic Exchange Quarterly. [Online] Available:

http://www.thefreelibrary.com/Exploring+writing+approaches+in+Chinese+EFL+class.-a0138703668 (September 22, 2005)

Zimmaro, D. M. \& Cawley, J. M. (1998). Concept map module. Schreyer institute for innovation in learning, The Pennsylvania State University.

Zipprich, M. A. (1995). Teaching web making as a guided planning tool to improve student narrative writing. Remedial and Special education, 16(1), 3-15. doi:10.1177/074193259501600102, http://dx.doi.org/10.1177/074193259501600102

Appendix: Instructional Material

1. What is a concept map?

Concept map is a graphic representation of ideas and concepts. It consists of concepts or nodes linked by labeled lines to show relationships and inter-relationships between terms. Concepts are arranged hierarchically so that the most inclusive, subsumptive concepts appear at the top of the map, with less inclusive, subordinate concepts below (Jonassen \& Grabowski, 1993, p.439). (Figure 1)

Concept mapping as a learning tool

- To summarize reading materials

- To organize knowledge domains

- To organize ideas for writing and research

- To plan your research project and identify the variables in it

- To fix learned materials in long-term memory

- To revise effectively for examination

2. Uses of concept mapping

- Develop an understanding of a body of knowledge

- Explore new information and relationships

- Access prior knowledge

- Gather new knowledge and information

- Share knowledge and information generated

3. How to organize our thoughts through concept mapping

A concept map is simply a way to visually display the concepts and relationships among ideas. This will help you to further organize your ideas and define your topic. It allows you to quickly write down your ideas and then see the organization of your topic. As you map, think about what issues you would like to focus on related to the main idea. Also think about the ways you will collect data and present the material Later you can return to your concept map as you create your outline. You can turn each level of bubbles (main topic, subtopics, etc.) into a level on your outline. This is a way for you to gain exposure to multiple dimensions of a topic that you might not have considered. To create a concept map you have to follow the following steps:

a) Identify the general/broad topic that you are interested in. 
Example: You are interested in the general topic of obesity

b) Brainstorm on the general topic and list all the concepts and themes that are related to the topic on a large piece of paper. Keep the concepts as concise as possible

c) Using unlined paper, write the main theme in the center of the page.

d) Take the other concepts identified in the brainstorming and connect them to the center concept. You can use other organizational patterns such as branches, arrows or groups. More important ideas should be put nearer to the center and less important ones closer to the edge. Identify the relationship between the concepts

e) After the map has been created, look at the organizational patterns to see if the pieces fit together and make sense and if there is anything missing. After the map has been created, look at the organizational patterns to see if the pieces fit together and make sense and if there is anything missing

4. Critical questions

After you created the map, you may ask yourself the following questions:

- What is the central word, concept, research question or problem around which to build the map?

- What are the concepts, items, descriptive words or telling questions that you can associate with the concept, topic, research question or problem?

- What is said about the concepts? Record the quotes or paraphrase.

5. Practice concept mapping

- Think about the sport that you most like. Then try to map out the general and specific ideas on a diagram. Figure 2 represents one example. (Figure 2)

6. Some tips on making concept maps

- Use a top down approach, working from general to specific or use a free association approach by brainstorming nodes and then develop links and relationships. Use different colors and shapes for nodes and links to identify different types of information. Use different colored nodes to identify prior and new information. Use a cloud node to identify a question.

- Gather information to a question in the question node.

7. Final words

- Different students may have different ways to represent what they think. Your concept map should reflect your information of a topic. It is always advisable to write down notes describing what you have mapped.

8. Sample Tasks

A. Create concept maps according to the following topics and compare yours with other students.

- travel

- recreation

B. Identify the concepts and fill in the concept map boxes. Figure 3 exemplifies one. (Figure 3)

Table 1. Means and standard deviations for pretest and posttest scores on writing achievement test

\begin{tabular}{|c|c|c|c|}
\hline & M & SD & N \\
\hline Pretest & & & 30 \\
\hline Experimental group & 14.00 & 1.31 & 30 \\
\hline Control group & 14.01 & 1.56 & \\
\hline Posttest & & & 30 \\
\hline Experimental group & 17.03 & 0.92 & 30 \\
\hline Control group & 15.55 & 1.10 & \\
\hline
\end{tabular}

Table 2. ANCOVA on Post writing Scores by Group (experimental vs. control), using Pre writing as a Covariate

\begin{tabular}{|c|c|c|c|c|c|}
\hline Source & $\begin{array}{c}\text { Type III sum } \\
\text { of squares }\end{array}$ & Df & Mean square & F & Sig. \\
\hline Pretest & 41.257 & 1 & 41.257 & 124.52 & .000 \\
\hline Group & 33.437 & 1 & 33.437 & 100.92 & .000 \\
\hline Error & & & & .27 & .60 \\
\hline
\end{tabular}




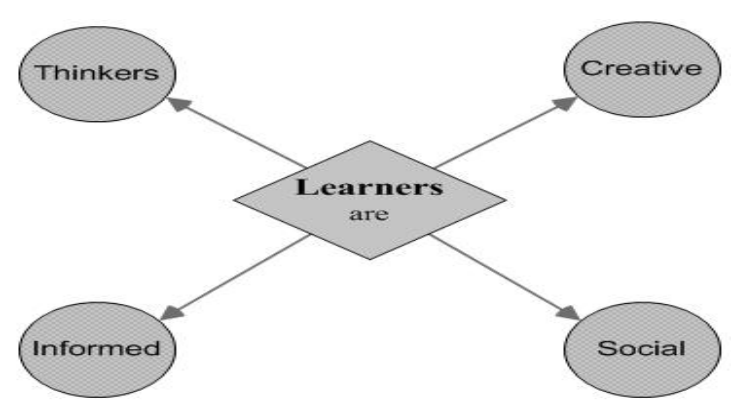

Figure 1. Example of concept mapping

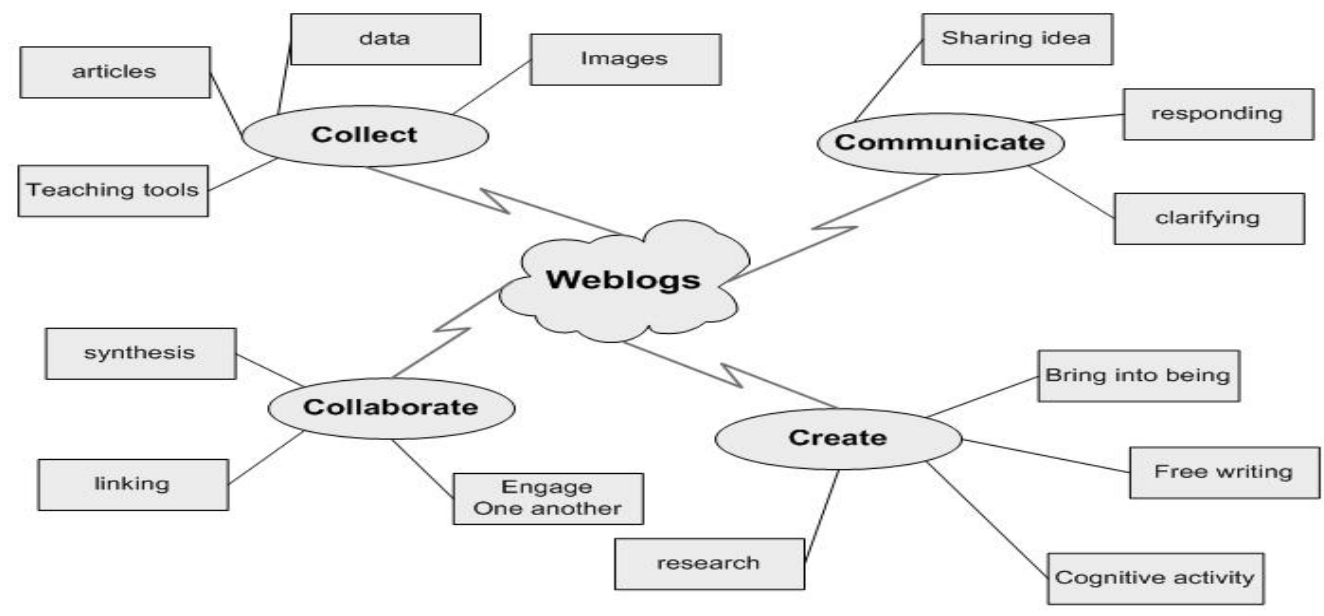

Figure 2. Concept mapping for weblogs

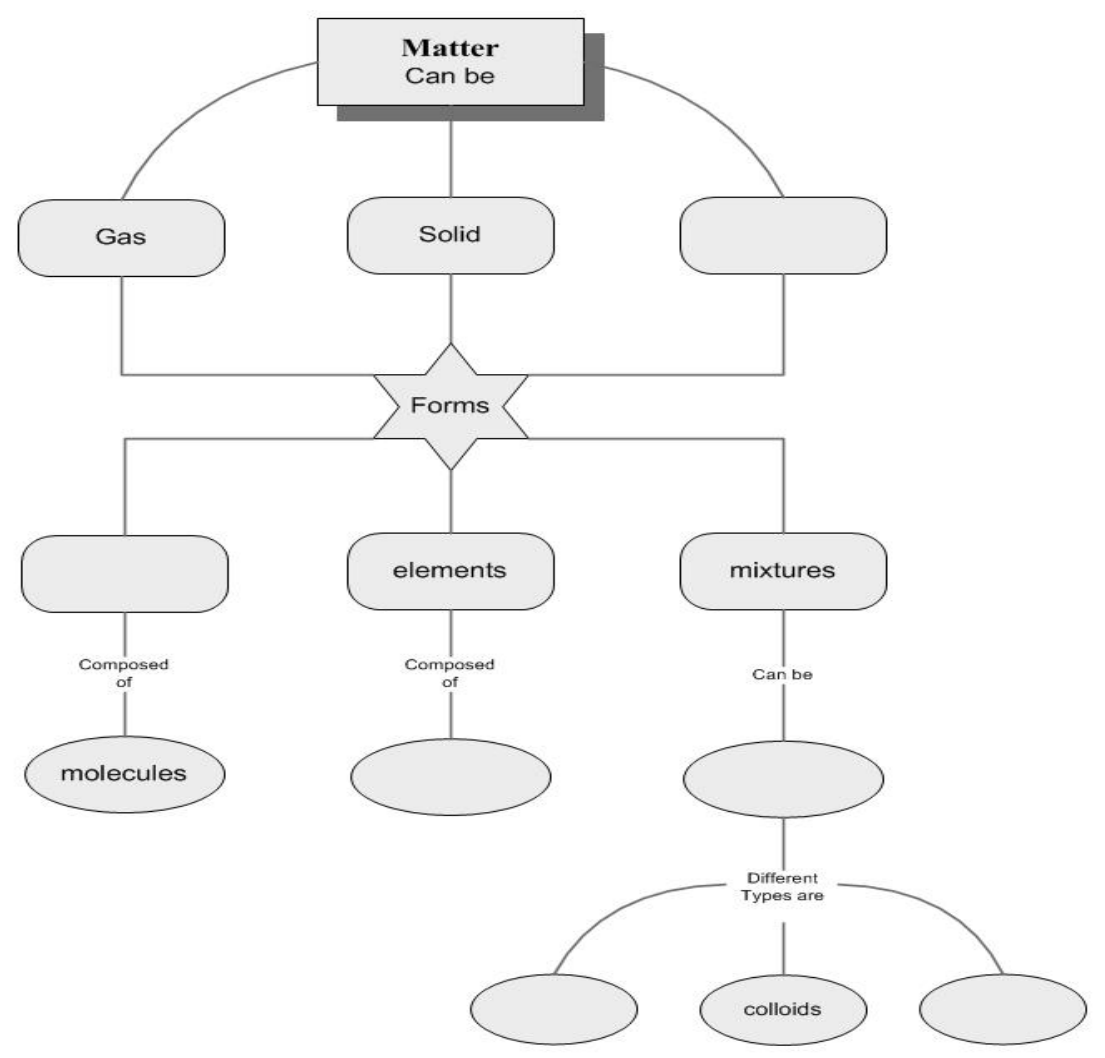

Figure 3. Example of an incomplete concept map 